\title{
PROPOSAL FOR A PESTICIDE RISK REDUCTION POLICY FOR NEW ZEALAND
}

\author{
M. WATTS \\ Soil and Health Association of New Zealand Inc. \\ PO Box 46-076, Herne Bay, Auckland
}

\begin{abstract}
New Zealand is one of the few OECD countries to have no pesticide risk reduction policy. Mounting pressure to develop such a policy is in part internal (increasing recognition of environmental contamination, community concern about spray drift); and in part external (the OECD Pesticide Risk Reduction Project; export market demands). Much criticism has been levelled at policies which, like Sweden's, include specific targets to reduce the quantity of active ingredients used. Yet analyses of Sweden's relative toxicity equivalents shows that a significant reduction in risk as well as quantity has been achieved. This paper presents elements of a proposed risk reduction policy for New Zealand.
\end{abstract}

Keywords: hazard, pesticide, policy, risk, reduction.

\section{INTRODUCTION}

Ever since Rachel Carson's classic “Silent Spring”, published in 1963, pressure to reduce the risks from plant protection products has been increasing world-wide. This pressure, together with mounting evidence of environmental contamination, has resulted in a gradual shift in thinking by policy-makers and over the last fifteen years there has been a steady move towards national (and international) policies of risk reduction. Britain and the Netherlands were amongst the first to pay at least lip service to a pesticide reduction policy: in 1983 the Dutch Ministry of Agriculture announced its aim of reducing use (Jansmaet al. 1993); also in 1983 the U.K. government agreed "to reduce use of pesticides to a minimum consistent with efficient food production" (Pesticides Trust 1992). It was Sweden however that installed, in 1986, the first comprehensive plan to reduce the risks associated with pesticide use. Korea and Australia are the countries to have most recently stated their intention of developing national risk reduction policies.

New Zealand has never had a pesticide policy, let alone a pesticide risk reduction policy, and in this we are conspicuous, especially amongst OECD countries. Pressure is mounting for New Zealand to develop a comprehensive policy, exerted in part by the OECD Pesticide Risk Reduction Project which is encouraging all member countries to implement such a policy, in part by our prominent lack of policy making us susceptible to market place discrimination, but not least of all by mounting internal pressure. Whereas in the past there has been an inclination towards the view (in the absence of real data) that New Zealand's use of pesticides is comparatively low, recent figures (OECD 1996) reveal that there is no room for complacency: New Zealand's rate of use on arable and fixed crops is twice that of the OECD average (refer Table 1). Evidence of groundwater pollution continues to accrue (e.g. Close 1995). Spray drift issues have not been resolved, communities remain divided, and some growers fear the potential restrictions of the Agricultural Chemical Trespass Bill.

\section{POLICY ELEMENTS}

An in-depth analysis of pesticide risk reduction policies is beyond the scope of this paper (refer instead Watts and Macfarlane 1997). However it is important to tease out those elements which may have contributed to their success or otherwise, and which should be considered in developing a New Zealand policy.

TABLE 1: Average pesticide use in OECD countries (arable and permanent

Proc. 50th N.Z. Plant Protection Conf. 1997: 498-505 
crop land).

\begin{tabular}{lc}
\hline Country & tonnes $/ \mathrm{km}^{2}$ \\
\hline Canada & 0.08 \\
Austria & 0.24 \\
Australia & 0.26 \\
UK & 0.44 \\
Netherlands & 1.21 \\
Japan & 1.45 \\
New Zealand & 0.43 \\
OECD average & 0.22 \\
OECD Europe average & 0.42 \\
\hline
\end{tabular}

Source: OECD 1996.

There are a number of elements which these policies have in common:

1. All focus on increasing farmer implementation of systems with a lower requirement for chemical pesticides - principally integrated pest management (IPM), or integrated crop management; some support conversion to organic systems.

2. In all policies actual pesticide use is voluntary, with one exception: the use of soil sterilants in Dutch agriculture is limited to once every four years. Some include reduction targets mandated by legislation - nevertheless the actual reduction in use by farmers is voluntary.

3. All polices focus attention and financial resources on improved extension services and increased research - principally into growing with lower pesticide use.

4. All policies emphasise safer and more efficient pesticide use through applicator training, farmer education programmes and sprayer calibration. In some, the applicator training has become compulsory. Ontario, Canada is notable for having had a voluntary training programme which became compulsory at the request of farmers (Rowland 1996).

5. Widespread consultation, involvement of, and cooperation with all interested parties is regarded as being essential to achieving acceptance of the programmes, and hence to achieving their objectives.

Other elements were evident in some policies but not in others:

1. Financial measures such as subsidies for conversion to organics, or for implementation of IPM; and taxes on pesticides designed to reduce their use.

2. The re-registration of all pesticides with the purpose of removing the more hazardous products from the market.

3. Most, but not all, policies include quantitative targets or goals, as measures of risk reduction (refer Table 2).

\section{Targets}

Whilst most of these policy elements are recognised as vital to the policies concerned and have therefore attracted little attention, controversy has raged around the issue of targets and appropriate measures of risk reduction. There is some opinion that a good pesticide risk reduction policy should include a quantitative target or targets, for two reasons:

1. The need for a focus. The experience of other countries has indicated the value of a target in focussing attention on the policy objective and providing a driving force for attitudinal changes. The Netherlands 1983 policy of reduced pesticide use and implementation of IPM had no targets and progress was inadequate; as a result the Multi-Year Crop Protection Plan (MYCPP) was developed, with quantitative targets for volume reduction and emission reduction; the result was an improved uptake of IPM, lower pesticide use, and lowered emissions of pesticides into the 
environment (Reus 1997). Vibeke Bernson (Swedish Chemical Inspectorate) and Anders Emmerman (Swedish Board of Agriculture) are adamant that a quantitative goal was vital to achieving the progress made in Sweden(Bernson 1997; Emmerman 1997).

2. The need for measurements of progress. The U.K. introduced a policy of pesticide minimisation in 1983; in 1990 it reintroduced the policy, and then in 1995 a government-sponsored meeting of interested parties identified the need to establish methods of measuring progress. A problem innate in a policy without clear goals or methods of measurement is that the absence of evidence can be interpreted in two ways: either progress is being made but cannot be clearly identified, or progress is not being made because of policy inadequacies. A method of measuring progress is a vital feedback mechanism for directing policy changes necessary for meeting the policy objectives.

TABLE 2: Measures of risk reduction: Sweden to Korea (Watts and Macfarlane 1997).

\begin{tabular}{lcccccc}
\hline Country & Year & $\begin{array}{c}\text { Period of } \\
\text { Programme }\end{array}$ & Target(s) & & \\
& & Volume & Frequency & Emissions \\
Air & GW $^{1}$ & SW $^{2}$ & IPM $^{3}$
\end{tabular}

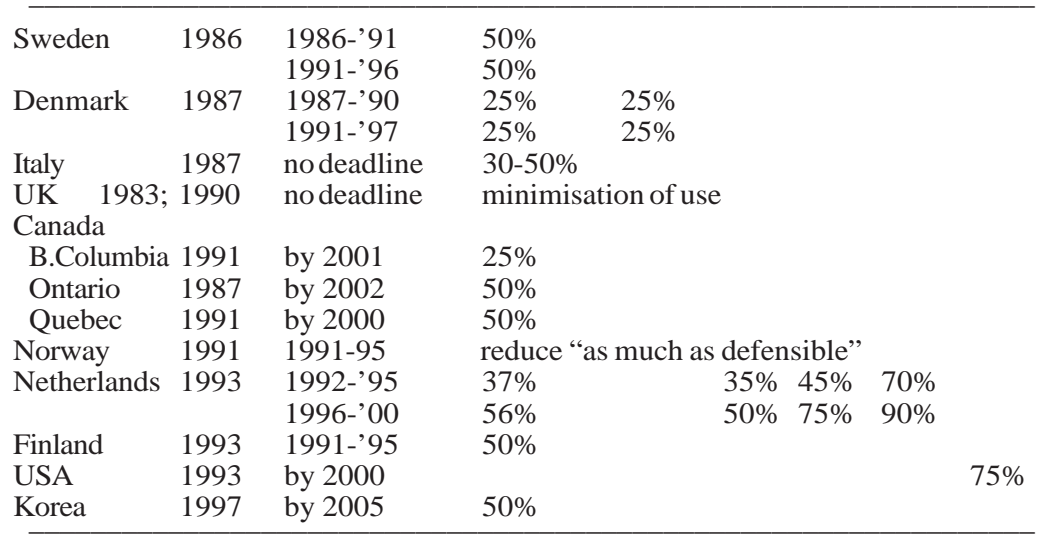

${ }^{1}$ Groundwater and air

${ }^{2}$ Surface waters

${ }^{3}$ Refers to the implementation of IPM

\section{Measures of risk reduction}

The real difficulty lies in the provision of targets that adequately measure a reduction in risk. The most commonly used targets have been those of a specified reduction in the total volume of active ingredients used in agriculture. Quite rightly these targets have been criticised for failing to adequately portray changes in risks, largely because most of the volume reduction achieved has been through substitution of low-dosage herbicides for high-dosage herbicides - the resultant volume reduction does not necessarily equate to a risk reduction. Sweden has defended its target, firstly on the basis that this was the best method available at the time for providing a quantitative measure of risk reduction (this being the real aim of the programme) (National Board of Agriculture 1988; Ekstrom and Bernson 1995); and secondly by way of a retrospective risk analysis. Using relative toxicity equivalents as indices for measuring risk, Ekstrom et al. (1996) demonstrated that a $61 \%$ reduction in volume averaged over two comparative periods 1981-1985 and $1990-94^{1}$ provided the following reduction in risks: 
- the reduction of residues in selected fruit and vegetables - about $10 \%$;

- the reduction in the acute toxicity to which pesticide users are exposed $-71 \%$;

- the reduction in the actual number of reported poisonings - these decreased forwork place exposure but increased for domestic poisonings.

However such a retrospective analysis, whilst serving to prove that Sweden's volume reduction programme did achieve risk reduction in some areas, is an inadequate method of measuring risk from the outset (what happened to chronic health risks, and to ecological risks?). With the increasing development of pesticide risk reduction policies has come an intense interest in finding more appropriate indicators of risk reduction. Two principal types are being pursued: the development of indicators to measure progress in risk reduction, and the development of indicators to measure a reduced reliance on pesticides by virtue of increased implementation of IPM practices. This proposal is concerned with the former of these.

\section{Assessment systems}

Since the initial development of Metcalf's IPM rating for insecticides in 1975, many assessment systems have emerged and will continue to emerge. There are a number of problems inherent in the systems and criticism abounds - Levitan et al. (1995), Levitan (1997) and Hart (1997) provide good critiques. However a brief description of the various types is a necessary background for the proposed New Zealand system.

There are two distinct types of assessment systems based on their intended purpose: decision aids for farmers and growers, and policy tools for governments. Examples of the former include the Environmental Yardstick for Pesticides (EYP) developed in the Netherlands (Reus 1993) ${ }^{2}$ and the PestDecide model developed for the Australian apple industry (Penrose et al. 1995). It is the later type, the policy tools, that are central to this paper - the purpose being the development of such a tool for a risk reduction programme in New Zealand. Some of the assessment tools have been designed for specific purposes such as groundwater protection, and their narrowness of function and complexity render them inappropriate for a New Zealand policy.

\section{THE NEW ZEALAND POLICY PROPOSAL}

The objective of a New Zealand policy should be the continuous reduction of risks to human health, the agroecosystem, and the wider environment resulting from pesticide use. It should include agricultural, horticultural, forestry, local authority, utility and domestic pesticide use, since all these uses affect the environment and people: pressure for risk reduction should not be borne by the farmer/grower alone.

The policy should, like its international predecessors, focus on research, extension, training, education, and cooperation. It could provide financial carrots and sticks. It may require some legislative changes. But it must also include a quantitative target(s) which support the policy objective and which provide a feedback mechanism to ensure the policy elements are adequate.

Volume reduction alone is inadequate. A good risk reduction indicator requires accurate inputs of hazard and exposure, but there is so little exposure data available for New Zealand that the development of such an indicator is not currently feasible (refer Table 3 for exposure factors regarded by participants at the 1997 OECD Pesticide Risk Reduction Workshop as requiring consideration for a risk indicator).

The author proposes that, in the absence of adequate exposure data, New Zealand develops a total pesticide use hazard scoring system which would provide a quantitative target for reduction, and which would provide a policy feedback tool appropriate to our current level of data and knowledge - a method of stimulating and measuring a reduction in the hazards associated with pesticide use.

${ }^{1}$ The actual reduction in volume over the 10 year period of the reduction programme (1986-1995) was 71\% (AGROW 1996).

2 The EYP has been expanded for use as an ecolabelling tool and for evaluating the MYCPP (Reus 1997a). 
TABLE 3: Some exposure factors to consider in a pesticide risk indicator (Watts 1997).

\author{
total quantity used \\ area treated \\ application rates \\ frequency of application \\ formulation \\ crop type \\ timing of application (eg crop stage) \\ method of application \\ tank mixture combinations
}

\author{
residues in food and drinking water \\ dietary intake \\ processing information \\ number of users \\ level of training \\ use of protective clothing \\ type of packaging \\ climatic factors
}

THE NEW ZEALAND PESTICIDE HAZARD SCORING SYSTEM

The purposes of the Hazard Scoring System (HSS) is to compile quantitative indicators of hazards associated with pesticide use, to monitor changes in these over time, to encourage a change in attitude and behaviour to bring about a reduction in risk from pesticide use, and to provide a policy corrective mechanism. This model is therefore intended for use at a national level, not at a crop level; it is not a tool to assist individual farmers use choices as are those of Reus (1993), Penrose et al. (1995), etc. ${ }^{3}$

\title{
Hazard indicators
}

Indicators of hazard are required for each of the two principal areas at risk from pesticide use: human health and the environment (including the agroecosystem). Table 4 identifies those proposed for the HSS, based on those considered by participants at the 1997 OECD Pesticide Risk Reduction Workshop to be of importance in a risk reduction indicator.

TABLE 4: Proposed indicators for a Hazard Scoring System.

\begin{tabular}{ll} 
Human Health & Environmental \\
\hline Acute oral, dermal and inhalation & Earthworms \\
Skin and eye irritation & Beneficial insects \\
Sensitisation & Bees \\
Subchronic and chronic NOELs & Aquatic plants,invertebrates, fish \\
Endocrine disruption & Birds \\
Neurotoxicity & Non-target terrestrial invertebrates \\
Immunotoxicity & Secondary poisoning \\
Carcinogenicity & Soilmicro-organisms \\
Mutagenicity & Bioconcentration \\
Reproductive effects & Persistence in soils \\
& Leaching potential \\
\hline
\end{tabular}

\section{Scoring mechanism}

It is not the intention of this paper to develop the mechanics of the system, but rather to propose the overall concept of its use within a policy framework. Hence only a brief outline of a proposed scoring mechanism is provided.

Each pesticide is allocated a numerical score for each indicator of hazard, based on a predetermined scale. The scores are summed to provide a total hazard score for each pesticide, in two separate categories - health and environment. Each of these is multiplied

\footnotetext{
${ }^{3}$ Use of such a system at the national level should note preclude individual agricultural sectors using decision aids such as PestDecide, or from developing their own systems (eg ENZA International's proposed Pesticide Points System, Walker et al. 1997).
} 
by its total use volume to provide a total hazard figure for each pesticide in the two separate categories of health and environment. All pesticide total hazard scores can then be summed to provide an overall unitless figure for hazard to New Zealand's health and the environment.

Although it would be mathematically simple to add the hazard scores for health and environment to achieve one figure, this would presuppose that the two categories are of equal merit, that the initial scoring scales are quivalent, and that there are the same number of hazard indicators for both. Any other method of combination would require a societal decision on the relative importance of the health and the environmental hazards. Such a decision would of course have to be very transparent, and very cooperative. Additionally if the scores for the two components are retained separately, it is possible to ascertain that over time one component is not increasing as the total decreases, disguised by the greater decrease of the second component.

\section{The target}

The dual scores for hazard to health and to the environment could then be used to develop targets, with timed reduction phases, designed to drive attitudinal and behavioural changes. If the estimate of today's hazard were to be say 20,000 units then a policy could develop a risk reduction goal of reducing that hazard score by $50 \%$ in 5 years, for example.

If the quality of pesticide use data were to allow it, total hazard scores could be retained separately for agricultural/horticultural, urban and utility usage. This would improve the effectiveness of the tool in focussing attention on areas where improvements are most needed. Such a focus may have an advantage in stimulating changes, as well as directing policy.

\section{Problems}

One of the greatest challenges to all scoring systems is the availability of accurate hazard data, especially in the ecological area. There are three separate issues, each of which challenge the accuracy of the systems in different ways:

- Lack of data on the interactive and long-term effects of pesticides at ecosystem levels, the hazards relating to so-called inerts and adjuvants in pesticide formulations; and to mixtures of pesticides.

- Lack of data for some pesticides with respect to those hazards which have been included in the scoring system. Several countries have increased their registration requirements for toxicological data, and it is likely that greater pressure will be exerted both for these datasets to be expanded, and for other countries to follow suit. Meanwhile, options for handling this situation include awarding an arbitrary and high/median/low score for that hazard, or an estimate based on structure and activity.

- Even where data is available, variations in test protocols of different research laboratories may limit the validity of comparisons (Levitanet al. 1995). However the OECD's project to harmonise pesticide registration procedures and standardised laboratory procedures may improve matters. The future outlook therefore is for a greater availability of standardised data relevant to an increased number of toxicological and ecotoxicological impacts for pesticides.

Perhaps an even greater challenge to the use of a scoring system in New Zealand is access to adequate use data, even at a national total use level. Such data is not however completely lacking, and until better collection is achieved, either mandated by regulation, or with the voluntary assistance of the chemical and agricultural industries, then estimates would need to be made on the basis of available information.

\section{CONCLUSION}

New Zealand should delay no longer in developing a pesticide risk reduction policy; we already lag behind most OECD countries and the continued absence of such a policy challenges any claim of environmental risk management in this country. The growers groups developing their own risk reduction approaches to pesticide use are to be encouraged, but there is also a need for a national policy approach, to incorporate the large pastoral sector, the utility and the urban sectors and other disparate groups of users. It is unfair to expect some pesticide users to carry the burden of risk reduction for the entire 
country; reducing risk is necessary for the tourist image, the environment and for the health and safety of the entire population of New Zealand, as well as for the export markets.

It is the author's view that a comprehensive scoring system is needed in order to progress a risk reduction approach to pesticide use. It is likely to be some time before adequate risk indicators are developed, and an even longer time before New Zealand has adequate exposure data on which to base an acceptable risk indicator. But sufficient hazard data is already available through the registration processes, within New Zealand and internationally, to make the use of a Hazard Scoring System a viable policy option. The proposed system is a rational and pragmatic approach to dealing with the lack of exposure data, the accurate assessment of which is currently not possible for the wide range of pesticide uses. Exposure does play a vital role in risk reduction, but the HSS is posited as only one part of a wider policy; other elements of which should address exposure issues. The HSS could also be used as the basis of a differential polluter-pays tax on pesticides.

One thing is sure, whatever policy is finally developed, widespread consultation, cooperation and involvement of all interested parties are absolutely essential for its success. If the policy does truly reduce the hazards and exposure (and hence risk), is transparent so that hazard reduction can be measured and can be seen to be occurring, then it is very possible that this issue of pesticides, which has created passionate antagonism and torn rural communities apart, can finally be resolved. If the policy is inadequate, and pays only lip service to risk reduction, then a great opportunity will have been lost.

\section{REFERENCES}

AGROW, 1996. Swedish plan to move from use to risk reduction, AGROW World Crop Prot. News (251): 11.

Bernson, V., 1997. Pers. Comm. OECD Workshop on Pesticide Risk Indicators, Copenhagen 21-23 April 1997.

Close, M., 1995. National Survey of Pesticides in Groundwater: 1994. Institute of Environmental Science and Research Limited, Christchurch, New Zealand.

Ekstrom, G., and Bernson, V., 1995. Swedish pesticide policies 1972-93: risk reduction and environmental charges. Rev. Environ. Contam. Tox. 141: 27-70.

Ekstrom, G., Hemming, H. and Palmborg, M., 1996. Swedish pesticide risk reduction 1981-1995: food residues, health hazard, and reported poisonings. Rev. Environ. Contam. Tox. 47: 119-147.

Emmerman, A., 1997. Pers. Comm. OECD Workshop on Pesticide Risk Indicators, Copenhagen 21-23 April 1997.

Hart, A., 1997. Key characteristics of pesticide risk indicators used as policy tools: a comparison of 11 indicators. OECD Workshop on Pesticide Risk Indicators, Copenhagen 21-23 April 1997.

Jansma, J.E., van Keulen, H. and Zadoks, J.C., 1993. Crop protection in the year 2000: a comparison of current policies towards agrochemical usage in four West European countries. Crop Prot. 12(7): 483-489.

Levitan, L., Merwin, I. and Kovach, J., 1995. Assessing the relative environmental impacts of agricultural pesticides: the quest for a holistic method. Agric. Ecosys. Environ. 55: 153-168.

Levitan, L., 1997. An overview of pesticide impact and risk assessment systems (pesticide riskindicators). OECD Workshop on Pesticide Risk Indicators, Copenhagen 21-23 April 1997.

National Board of Agriculture, 1988. Action Programme to Reduce the Risks to Health and the Environment in the Use of Pesticides in Agriculture (Summary). Sweden.

OECD, 1996. Environmental Performance Reviews: New Zealand. Organisation for Economic Co-operation and Development, Paris.

OECD, 1997. Workshop on Pesticide Risk Indicators, Copenhagen 21-23 April 1997. Penrose, L.J., Thwaite, W.G., Maguire, M., and Morris, K., 1995. PestDecide: a decision support system to assist growers choose pesticides for use on apples grown for 
accreditation under integrated pest and disease management. NSW Agriculture, Australia.

Pesticides Trust, 1992. Pesticides: Missing the Target. A report for WWFU.K., London, U.K.

Reus, J.A.W.A., 1993. An environmental yardstick for pesticides.Proc. 46th N.Z. Plant Prot. Conf.: 91-96.

Reus, J.A.W.A., 1997. Pers. Comm. OECD Workshop on Pesticide Risk Indicators, Copenhagen 21-23 April 1997.

Reus, J.A.W.A., 1997a. The environmental yardstick for pesticides - state of affairs April 1997. Unpublished paper, Centre for Agriculture and Environment, Utrecht, Netherlands.

Rowland, P., 1996. Recent changes in international crop protection practices: the growing trend to reduce pesticide use and pesticide risk. Bureau of Resource Sciences, Parkes ACT, Australia.

Walker, J.T.S., Hodson, A.J., Batchelor, T.A., Manktelow, D.W. and Tomkins, A.R., 1997. A pesticde rating system for monitoring agrichemical inputs in New Zealand horticulture. Proc. 50th N.Z.Plant Prot. Conf.: (this volume).

Watts, M.A., 1997. Report on the OECD Workshop on Pesticide Risk Indicators, Copenhagen 21st-23rd April 1997.

Watts, M.A., and Macfarlane, R., 1997. Reducing Reliance: a Review of Pesticide Reduction Initiatives. Pesticides Action Network Asia and the Pacific, Penang, Malaysia. 